\title{
Patient Satisfaction with Health Care Services in Albania
}

\section{Rezarta Kalaja PhD Candidate}

\author{
Lecturer, Faculty of Professional Studies, University of Durres; rezartak@hotmail.com
}

\section{Halit Xhafa Prof. Dr}

Lecturer, Faculty of Economy, University of Tirana; xhafah@gmail.com

Doi:10.5901/ajis.2016.v5n1p295

\section{Abstract}

\begin{abstract}
Health sector in Albania suffers from inefficiencies and disparities. Money under the table are very common especially in public institutions comprising almost more than half of the total health expenditures spent by the government for this sector. Furthermore, the poorest individuals are not part of the mandatatory health insurance schemes exacerbating even more their economic conditions. Moreover health performance indicators are not clearly defined, making health service quality remaining a significant concern. For this purpose there is an absolute need of evaluating health sector performance which is closely related to the establishment of indicators as part of the general assessment of the health system, where the main goal is its consolidation and improvement of services provided. Thus, for a better assessment of health care it is important to evaluate all indicators as per their scientific importance, including reliability, validity and use. In Albania indicators' used are far from the ones used worldwide; still their utilization is reported as a significant progress and are considered as a positive initiative for health sector performance measurement. However, still no efforts are made to introduce practices to assess health performance quality in hospitals along with integration of appropriate indicators and other instruments widely accepted for evaluation.
\end{abstract}

Keywords: patient satisfaction, health quality, gap, indicators, Albania

\section{Literature Review on Patient Satisfaction and Health Quality Services}

Studies related with patient satisfaction are carried out widely and mainly for the need and desire to better understand different behaviours of individuals (Cronin et al. 2000), and its way of assessment varies as per definitions and asumptions made (Gilbert et. al.2004). Different perspectives associated with customer satisfaction measurement, include the expectancy-disconfirmation approach, the performance-only approach, the technical and functional dichotomy approaches, the service quality versus service satisfaction approach, and the attribute importance approach (Gilbert and Veloutsou, 2006).

While, Crowe et al. (2002) and Urdu (2002) independently of one another stressed out that patient' satisfaction is a cognitive evaluation but emotionally affected, and consequently is a subjective individual perception. Moreover, there is solid evidence that the most important determinants of satisfaction are interpersonal relationships and aspects of care. Later, Wolosin (2005) would consider patient satisfaction as an indicator of service quality and in his definition on sattisfaction, patient personal experiences were essential. Thus, satisfaction is patient's "voice" which is important because it reflects their relation with health care providers.

In other studies satisfaction is defined as a circular model that explains the relationship between satisfaction and loyalty. In fact Mc.Alexander (2003) would consider sattisfaction as loyalty ancestor, while Camper (2004) emphazise that loyalty drives expectations consumers, which in turn direct individuals's purchases and consumption processes. Satisfaction is also described as the value of the product or service which individuals assess depending on their expectations of experiences (Liljinder et al. 1995).

\subsection{Socio demographic factors and patient satisfaction}

Patient's satisfaction is increasingly being considered as a very important element of the health sector, due to the following reasons: (a) to compare several programs and systems of health care, (b) to assess service quality, (c) to identify what aspects of services need to be changed to increase patient satisfaction, and (d) to support healthcare 
organizations to identify their customers (Jackson et.al, 2001). All these aspects help policymakers, health care managers and physicians to identify reasons for the disappointment of patients and to design potential interventions to improve satisfaction of the health care system.

Patient characteristics such as age, sex, socio-economic status, education and marital status, are widely used in questionnaires as drivers to evaluate patient's expectations in health sector. According to Hall et.al (1990), Sitzia et.al (1997), Nasser et.al, (2012), Afzal et.al (2014), the older and poorer the people are the lower are their expectations, therefore they tend to be more satisfied with health care services. While more educated people tend to have lower satisfaction as they have the tendency to better understand their illness and this way they also pretend to get better services and communication by the medical staff.

Other similar studies conducted for the same reason had also confirmed the same findings that socio demographic factors are closely related with patient satisfactions where men and women show no differences but the older the patient were the more satisfied they were with the services provided compared to younger people (Schoenfelder et al., 2011).

\subsection{Determinants of patient sattisfaction}

In a highly competitive market in the industry of health care, managers should focus on achieving the highest estimations of patients on service quality and satisfaction to further improve. It also one of the sectors with the highest pace of development in developed and in developing countries (Dey, 2006). Patients are now considered as health service consumers, able to decide where to get this kind of service as per their needs (Wadwha 2002), that is why service quality and patient satisfaction are two important health products that serves as quality assesors (Ygge and Arnetz, 2001; Jackson et al. 2001; Zineldin, 2006).

For this reason health care managers should identify factors that mostly determine patient satisfaction to use as tools for assessing health care provided. In order to understand these factors that influence patient satisfacion various researchers have disclosed different dimensions of perceived service quality of as the main gauge and meaningful quality of health care. Determinants of patient satisfaction from different studies show clear links between satisfaction and personal patient characteristics (Peters et al. 2006). It has long been recognized that patient satisfaction is a multidimensional element and it varies from different aspects (Soegaard et al., 2008). A clean, queit and well-organized hospital, of modern equipments influence results on patient service quality as per Andaleeb (2001). However as per Bamisec, et al. (2008) this is not always true because even in hospitals with shortage of all these aspects it is proven that patients were still satisfied. Communication is also a very important element that affects patient satisfaction. If patients do not feel well informed and close to doctors or unclear about their health status, it can also affect their healing process.

Donabedian philosophy on patient satisfaction is based on the fact that the definition of indicators that measure health quality leads automatically to satisfaction assessment. Indicators include the entire process, the structure and also the final treatment products. Indicators related to structure are medical determinants such as medical staff, their trainings and equipments and non-medical determinants such as infrastructure, equipment, premises, ect. While process indicators are related with the processes that the medical staff offers to patients throughout the course of treatment (Sitzia et al. 1997; Donabedian, 1980). In general patient's expectations and perceptions on past experiences with health care providers are key determinants of patient satisfaction worldwide. These aspects are intertwined and connected with each other and can influence at the same time on patient satisfaction (Nasser et. al.2012).

From the above it is clear that patient satisfaction is closely and directly linked with the perceived service quality and for this reason it is important to understand how to measure it to then assesss patient satisfaction. According to Satya (2003), individuals are dissatisfied for three reasons: (i) when service providers are not aware of quality dimensions and its importance for customers (ii) when service providers do not recognize customer priorities on the services and (iii) when service providers do not know service charachteristics that create quality dimensions. To assess patient satisfaction is not easy, as it requires: clear definition of objectives, identification of target population, accurate data assembly, and also a strategy for elaborating data collected. Finally satisfaction assessment allows the identification of potential problems and suggests ways to improve service quality of health service (Druss, 1999, Harris et al. 1999).

\section{Methodology}

The purpose of this study is to assess hospital care quality in Albania and patient satisfaction by also identifying dissimilarities between public and private hospitals. Also, this article aims to determine key factors that play a determinant role in patient satisfaction, as well as their order of importance, to give appropriate recommendations for improving both 
service quality and to increase patient satisfaction in health sector in the country. The carrying out of this study is based on a deductive approach, moving from theory to observation and is concerned with developing a hypothesis (or hypotheses) based on existing theory, and then designing a research strategy to test the hypothesis (Wilson 2013). Data are collected and will be further elaborated to test the hypothesis as below built on to achieve the objective set.

The first hypothesis:

$\mathrm{H}_{0}$ - There are no significant differences in patients' expectations on the dimensions of service quality between public and private hospitals.

$\mathrm{H}_{\mathrm{a}}$ - There are significant differences in patients' expectations on the dimensions of service quality between public and private hospitals.

The second hypothesis:

$\mathrm{H}_{0}$ - There are no significant differences in patient's perceptions on the dimensions of service quality between public and private hospitals.

$\mathrm{H}_{\mathrm{a}}$ - There are significant differences in patient's perceptions on the dimensions of service quality between public and private hospitals.

The third hypothesis:

$\mathrm{H}_{0}$ - There are no significant differences in the evaluation of gap "perception - expectations", of the dimensions of service quality between public and private hospitals.

$\mathrm{H}_{\mathrm{a}}$ - There are significant differences in the evaluation of gap "perception - expectations", of the dimensions of service quality between public and private hospitals.

In this survey participated over 820 hospitalized patients, but the sample size contains answers of only 800 of them, as 20 surveys didn't have the necessary information to be included in the study. Patients who participated in this survey were randomly selected thus they have different ages, education, level of incomes which make the sample as representative as possible.

Selection of the instrument is based in the respective literature, where one of the main instruments used worldwide to evaluate service quality is the one proposed by Parasuraman, Zeithaml and Berry $(1985,1988)$, called SERVQUAL. Through this instrument researchers can directly measure real perceptions on performance as well as patient expectations, where positive gap (discrepancies) of perceptions vs expectations show sattisfied patient and negative results show the contrary. Carrillat et al. (2007) believe that SERVQUAL instrument has representative and diagnostic importance in health sector, because through the comparison of real and perceived qualities along different dimensions, managers can identify weak areas that need to be improved (Parasuraman et al. 1994).

Initally the analysis start with the factorial weights test for each of the dimension and reliability coefficients. GAP values for all dimensions in public sector has factorial weights higher than 0.4 , meaning that all dimensions can be tested further, while alpha coefficient is 0.915 implying internal consistency between variables.

Likewise this analysis is carried out for the private sector and the results are similar. Later it is tested for multicollinearity between dimensions and the results shows that correlation coefficents are within the bands, which allow to build a multiple regression equation of GAP service quality and satisfaction of patients in public and private hospitals in Albania.

\section{Main Findings}

As earlier stated in this analysis were tested 800 hospitalized patients, out of which 650 patients or round $81.2 \%$ of them has been asked in public hospital while $17.8 \%$ of them received health services in private hospitals. Patients were also asked for service satisfaction during the time they had been hospitalized in both sectors and the results show that $37.9 \%$ of patients interviewed said they were very satisfied with services provided, followed by $29.4 \%$ of patients who said they were satisfied, while unsatisfied or partly satisfied patients were respectively $0.8 \%$ and $7.5 \%$. $24.5 \%$ of patients were neutral for patient assessment. Analysis also provides these results for the values of the gaps in both sectors, for each dimension. 
Graph 1: GAP values for each dimension in two sectors.

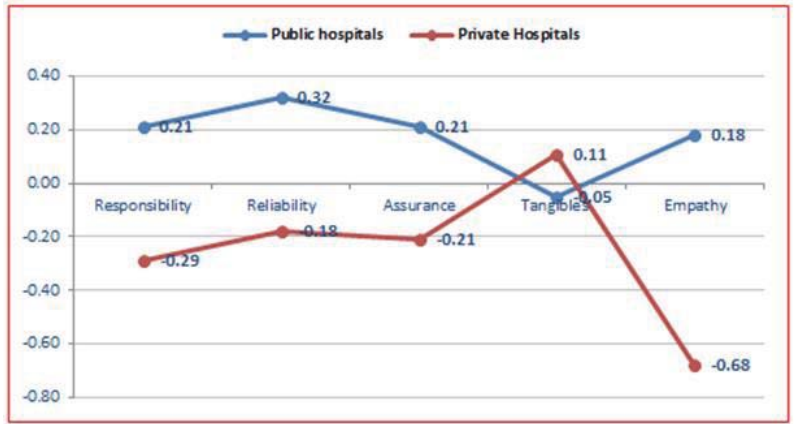

Source: Authors, 2016

For the first hypothesis that tests if there are significant differences in patients' expectations on the dimensions of service quality between public and private hospitals, Leven Test shows that $F=96,092$ have the value of Sig. $=0.000<0.005$ meaning that $\mathrm{H}_{0}$ is rejected because these two groups of patients have not homogenous expectations on service quality. This is also evident when comparing their standart values where DS sublic $=0.862$ while DS s. privat $=0.479$.

Moreover, it is estimated means comparison test where $t=-19161$ and $\mathrm{df}=403275$, while the corresponding value of Sig. (2-tailed) $=0.000<0.005$ meaning that between these two groups there are statistically significant differences, that is why $\mathrm{H}_{0}$ is rejected.

However, referring to the mean values where $M_{s . P u b l i c}=3.83$ andMs.Privat $=4.82$ meaning that expectations were higher in private hospitals. This is quite normal when comparing the costs of services provided in private hospitals because of the modernizations of tangibles they offer and also for doctors ability which sometime can be foreign ones assisting only private hospitals.

For the second hypothesis that tests if there are significant differences in patient's perceptions on the dimensions of service quality between public and private hospitals, Leven Test show that the groups of patients are not homogenous so it is important to assess also means comparison test where $t=-14.409$ and $\mathrm{df}=347.601275$, where the corresponding value of Sig. (2-tailed) $=0.000<0.05$ meaning that between these two groups there are statistically significant differences on the perception between hospitals, and that is why $\mathrm{H}_{0}$ is rejected. Referring to the mean values Ms.Public $=4.05$ and Ms.Privat $=4.71$ meaning that expectations were higher in private hospitals as it was also expected.

For the third hypothesis that tests if there are significant differences in the evaluation of gap "perception expectations", of the dimensions of service quality between public and private hospitals, Leven Test shows that two groups of patients are not homogenous to assess GAP values because Sig. $=0.000<0.005$. That is why the analysis continue with means comparison test where for $\mathrm{t}(4.432)$ and $\mathrm{df}=35.0786$ while corresponding value of Sig. (2-tailed) $=$ $0.000<0.05$ meaning that between these two groups there are statistically significant differences evaluation of gap "perception - expectations", between hospitals that is why $\mathrm{H}_{0}$ is rejected. In addition when referring to the mean values where Ms.Public $=0.1118$ andMs.Privat $=-0.1975$ meaning that the real assessment has been lower than expectations in private hospitals than in public ones.

To conclude the regression equations for GAP measured for public and private hospitals are as below:

Patient Satisfaction on service quality in public hospitals $=3.722+0.247$ (responsibility) +0578 (reliability) +0.130 (assurance) + 0151 (tangibles) + 0.371 (empathy)

Patient Satisfaction on service quality in private hospitals $=4709+0415$ (responsibility) +0489 (safety) +0803 (tangibles) +0.265 (empathy)

\section{Concluding Remarks}

As also outlined in the respective literature, patient sattisfaction is a psychological concept, and its assessment is considered as an individual jusdgement on any experience. For this reason SERVQUAL instrument used in this research carried out for hospitals in Albania, measures service quality based on real patient perceptions of service received and 
patient expectations prior of receiving hospital services. In this respect the results in different sectors (public and private hospitals) changes as patients' expectations were too different.

In public sector patients' expectations were not high and vary between dimensions. Higher expectations were related to medical staff assurance dimension as it is assessed as the highest one (over $55 \%$ of patients had expected the situation to be better), followed by reliability, responsiveness, empathy and tangibles (for the latter only $10 \%$ of hospitalized patient expected the situation to be very good and almost $40 \%$ of them expect the situation to be at least at average level). While in the private sector expectations were not different and do not vary as per dimensions. Patient assessment was persistent and almost $98 \%$ of them expect conditions to be good in every aspect, which undoubtedly affects the final results of the real gap between perceptions and expectations, to determine patient satisfaction in both sectors.

Because low expectations and estimations in service quality that hospitalized patients were provided in public health sector the gap proved to be positive in four dimensions, meaning that patients were satisfied with the services. The only negative evaluated dimension is related to tangibles which is somehow expected because of the poor conditions that public hospital have. From the analysis resulted that patients were satisfied with staff reliability, followed by responsibility and assurance at the same level and empathy.

However, the situation is completely different in private health sector, where the only positive gap evaluated is related to tangibles dimension, while all other dimension has negative gap although of low values. Patients were disappointed mainly from the medical staff empathy, followed by responsibility, assurance and reliability.

To conclude according to multiple linear regression for public sector in Albania, dimensions rank affecting and increasing mostly patient sattisfaction is: reliability, empathy responsiveness, tangibles and assurance, while for the private sector dimension rank is: tangibles, assurance, responsiveness and empathy.

\section{References}

Afzal M, Rizvi F, Azad AH, Rajput AM, Khan A, Tariq N. Effect of demographic characteristics on patient's satisfaction with health care. Postgrad Med Inst. 2014; 28:154-160.

Andaleeb, S. S. (2001). Service quality perceptions and patient satisfaction: a study of hospitals in a developing country. Social Science \& Medicine, 52, 1359-1370.

Carrillat, F. A., Jaramillo, F. \& Mulki, J. P. (2007). The validity of the SERVQUAL and SERVPERF scales: A meta-analytic view of 17 years of research across five continents. International Journal of Service Industry Management, 18(5), 472-490.

Cronin, J.J.J., Brady, M.K. and Hult, G.T.M. (2000), "Assessing the effects of quality, value, and customer satisfaction on consumer behavioral intentions in service environments", Journal of Retailing, Vol. 76 No. 2, pp. 193-216.

Crow $R$, Gage H, Hampson S et al. The measurement of satisfaction with healthcare: implications for practice from a systematic review of the literature. Health Technology Assessments 2002;6(32):1-244.

Dey, P.; Hariharan, S.; Brookes, N. (2006), Managing healthcare quality using logical framework analysis. Managing Service Quality. 16 (2): 203-222.

Donabedian, A. 1997. The quality of care: How can it be assessed? Arch Pathol Lab Med 121(11):1145-1150.

Druss GB. (1999). Patient satisfaction and administrative measures as indicators of the quality of mental health acre. Psychiatric Services, 50 (80): 1053- 1058.

Gilbert, G.R., \& Veloutsou, C. (2006). A cross-industry comparison of customer satisfaction. Journal of Services Marketing, 20(5), 298308.

Hall J.A., Dornan M.C. Patient socio-demographic characteristics as predictor of satisfaction with medical care: meta-analysis. Social science and medicine. 1990; 30: 811-8.

Harris EL, Swindle WR et al. (1999). Measuring patient satisfaction for quality improvement. Medical Care, 37(12):1207-1213.

Jackson JL, Chamberlin J, Kroenke K. Predictors of patient satisfaction. Soc Sci Med 2001; 51:609-20.

Liljander.V and Strandvik T (1995), The Nature of Customer Relationships in Services, Swartz T.A., Bowen D.E. and Brown S.W. (Eds) Advances in Service Marketing and Management, 4, JAI Press, London.

McAlexander, J., Kim, S., and Roberts, S. (2003), 'Loyalty: the influences of satisfaction and brand community integration'. Journal of marketing Theory and Practice, 11(4): 1-11.

Parasuraman, A., Zeithaml, E. V. \& Berry, L. L. (1988). SERVQUAL: a multiple items scale for measuring customers perception of service quality. Journal of Retailing, 64, 12-23.

Parasuraman, A., Zeithaml, V. \& Berry, L. 1985. A conceptual model of service quality and its implications for future research. $J$ Marketing 49(1):41-50

Parasuraman, A., Ziethaml, V. and Berry, L., (1994), "Moving forward in service quality research: Measuring different customerexpectations levels, comparing alternative scales and examining the performance-behavioral intentions link", Cambridge, Massachusetts: Marketing science institute, Report Number 94-114.

Stizia J, Wood N. (1997). Patient satisfaction: A review of issues and concepts. Soc Sci Med, 45(12): 1829-1843. 
Urden, K.D. (2002), "Patient satisfaction measurement: current issues and implications", Outcomes Management, Vol. 6 No. 6, pp. 12531.

Wadwha, S. S. (2002). Customer satisfaction and health care delivery systems: Commentary with Australian bias. [Electronic Version]. The Internet Journal of Nuclear Medicine. 1(1): 1539-4638.

Wilson J, (2013, December), "Essential of Business Research: A guide to doing your research project", SAGE second edition

Wolosin RJ. (2005). The Voice of the patient: A national representative study of satisfaction with family physicians. Q Manage Health Care, 14(3):155-164.

Ygge, B.; Arnetz, J. (2001), Quality of paediatric care: application and validation of an instrument for measuring parent satisfaction with hospital care. International Journal for Quality in Health Care; 13(1): 33-43.

Zineldin, M. (2006). The quality of health care and patient satisfaction: An exploratory investigation of the 5Qs model at some Egyptian and Jordanian medical clinics. International Journal of Health Care Quality Assurance, 19(1), 60-92. 